\title{
Grandeza e decadência de Fritz Haber ${ }^{1}$
}

A R K A N I M A A N*

Resumo Fritz Haber, prémio Nobel da química em 1918, ficou famoso por causa da síntese do amoníaco a partir do azoto atmosférico, resolvendo, consequente- mente, o problema dos fertilizantes. Mas ele é também o iniciador da guerra química e o inventor do funesto Zyklon B.

\section{Primeiros anos de vida}

Fritz Jacob Haber nasceu em Breslau (hoje, Wroclaw), em 1868, cidade que na época pertencia à Prússia. Três anos depois, a Alemanha unificou-se após uma brilhante vitória militar contra a França.

O pai de Fritz, Siegfried, judeu não praticante, importador de índigo natural, possuía um grande negócio de corantes, comércio que a unificação fez florescer e do qual a Alemanha, rapidamente estabeleceu o monopólio mundial. Uma imponente indústria química desenvolvia-se na nação, baseada nas imensas reservas de carvão e na exploração da destilação da hulha.

A mãe de Fritz Haber morreu logo após o parto. Acreditando que o filho suportaria melhor a tristeza da orfandade, Siegfried deu-lhe uma educação espartana. O resultado foi catastrófico: a criança, ao contrário, sentiu-se culpada pela morte da mãe. É bem verdade que, na Prússia, as educações rigorosas eram muito valorizadas. Elogiava-se a disciplina, o exército e o nacionalismo. O patriotismo servia de cimento para a coesão do país: apesar da unificação, ainda eram vivas as disputas regionais e religiosas que tantas vezes cobriram de sangue as páginas da história. Deus, Pátria e Ciência vão-se tornar, pouco depois, em credo do futuro Kaiser WiIhelm II. Eis as palavras que o soberano utilizou para felicitar Wilhelm Roentgen pela descoberta dos raios $X$ (1896): "Louvo Deus por conceder à nossa pátria alemã esse novo triunfo científico".

Após nove anos de viuvez, Siegfried casou-se com uma mulher jovem que Ihe deu três filhas. Apesar do carinho da madrasta, Fritz caiu em melancolia. No ano seguinte ao matrimónio, entrou no prestigioso Gymnasium de Breslau, onde recebeu instrução clássica de alto nível. Esse estabelecimento possuía alguns privilégios: o serviço militar obrigatório dos alunos era reduzido e os estudantes que aí obtivessem o Abitur (exame final) podiam entrar em qualquer universidade. Como era costume, na época, Haber dividiu a sua formação em química entre diversos centros, entre os quais as Universidades de Berlim e de Heidelberg. Nesta última, frequentou os cursos de Roberto Bunsen (1811-1899), cujo nome está associado a um bico de gás que ainda hoje ornamenta as mesas químicas. Haber vai obter em 1891 um doutoramento em química orgânica.
No final do século dezanove, as universidades alemãs estavam estreitamente ligadas às indústrias químicas de alta tecnologia, particularmente às de remédios e corantes. Qualquer nova substância que surgisse nas fábricas era imediatamente analisada nos laboratórios universitários. Da mesma forma, estes últimos forneciam aos industriais patentes para novos compostos. Os cientistas também circulavam nesta via de mão dupla, passando frequentemente das indústrias às universidades. Por conseguinte, o número era enorme: havia dez vezes mais químicos na Alemanha do que na França, por exemplo.

Após os seus estudos, Fritz Haber foi trabalhar na empresa familiar, preparando-se para a sucessão. Porém envolveu-se numa transacção comercial imprudente, colocando a firma em dificuldades económicas. Isso fez com que seu pai não se opusesse à ideia do filho de tentar uma carreira académica, mesmo sabendo que ela seria difícil: os rendimentos de um professor que não patenteasse uma invenção interessante eram incertos. Só os catedráticos recebiam salários adequados; os outros, tanto os mestres assistentes como os associados dependiam do número de alunos matriculados nos cursos deles.

\footnotetext{
*Professor de física e historiador de ciências (arkan.simaan@free.fr)

1 Versão portuguesa do artigo publicado no Bulletin des Professeurs de Physique et de Chimie, Maio de 2005, e na Association des Professeurs d'Initiation aux Sciences Physiques, 2005.
} 


\section{O baptismo}

Em 1892, Fritz Haber tornou-se luterano, abandonando ao mesmo tempo o judaísmo e o uso do segundo nome, Jacob.

Os amantes de psicologia verão em tal gesto uma vingança tardia de Fritz para com o pai: sem dúvidas, a conversão magoou os familiares, a começar por Siegfried.

No entanto, este baptismo ligava-se mais à compreensível ambição profissional de Haber: os empregos mais prestigiosos no exército e na administração eram reservados aos cristãos. Eis porque, muitos membros da comunidade judaica adoptavam então o cristianismo pensando em promoção (esta prática aumentou no século vinte, particularmente na década de 1920). Entretanto, nada garantia o sucesso: ninguém esquecia a origem dos indivíduos. Assim, em 1900, quando Haber postulou uma vaga de catedrático no Instituto Técnico de Karlsruhe, onde já ensinava como assistente havia um ano, ele foi rejeitado devido às suas ascendências judaicas. Dois anos depois, surgiu uma outra oportunidade na universidade de Viena. Infelizmente, os preconceitos não conheciam fronteiras. Após uma primeira opinião favorável, a sua candidatura foi descartada quando o conselho universitário soube que era "judeu baptizado".

Mudar de religião significou também, para Haber, o desejo de integrar-se na nação, sentimento disseminado em uma parte dos jovens judeus. Influenciados pela cultura alemã, muitos não seguiam as regras alimentares da comunidade e sentiam-se mais próximos das práticas cristãs do que dos costumes ortodoxos dos judeus da Europa Oriental. Tal era o caso de Fritz Haber. Imbuído de literatura, música e filosofia alemã, ele identificava cristianismo com germanismo, a ponto de se transformar numa caricatura de patriota. Pode-se até dizer que o patriotismo se transformou na sua nova religião. Ele jamais criticou publicamente as autoridades, independentemente da política do governo. Pouco antes de morrer, Haber, fugindo da Alemanha nazista, confessou-se arrependido: "So- mente hoje percebo o quanto fui patriota alemão".

\section{O casamento}

Em 1901, casou-se com Clara Immerwahr, nascida como ele em Breslau na comunidade judaica e também baptizada cristã. Um outro laço os unia: ela fizera um doutoramento em química talvez tenha sido o primeiro atribuído a uma mulher na universidade de Breslau. Dez meses depois da união, Clara deu à luz um filho, após uma gravidez problemática. A carreira dessa mulher brilhante, determinada, que conseguira romper preconceitos para estudar, foi demolida: na sombra espessa do marido, não conseguiu, nunca, encontrar um raio de Sol. "O que resta de mim, disse ela a um amigo em 1909, enche-me da mais profunda insatisfação (...) a maior parte deve ser atribuída à sufocante imposição da pessoa de Fritz (...) Quem não seja ainda mais egoísta e descortês (do que ele) estilhaça-se ${ }^{1}$." Clara traduzia, ocasionalmente, escritos do seu marido em inglês.

Na mesma época, Fritz Haber revelava obras de interesse químico: em 1898, editou o seu curso Grundriss der technischen Elektrochemie auf theoretischer Grundlage (Bases teóricas da electroquímica técnica), onde defendeu a necessidade de uma associação indústriauniversidade. No mesmo ano, elucidou a redução do nitrobenzeno no cátodo de uma célula electroquímica (que se tornou modelo de explicação para esse tipo de reacção) e em 1904, estudou o equilíbrio quinona-hidroquinona ao mesmo tempo em que inventava com Max Cremer o eléctrodo de vidro que permite a medição da acidez de uma solução. No ano seguinte, publicou Thermodynamik technischer Gasreaktionen (Termodinâmica das reacções gasosas técnicas) que exerceu uma influência decisiva no ensino e na pesquisa em termodinâmica.

\section{Espectro da fome no mundo}

Como alimentar a população que cresce de forma descontrolada? Eis aí uma das dificuldades dos governos europeus no final do século dezanove.
Na realidade, tratava-se da ressurreição da velha discussão maltusiana. Um século antes, o inglês Thomas Robert Malthus havia previsto um futuro sombrio para os seres humanos se a população crescesse mais do que os alimentos. A única alternativa para a humanidade, dizia ele, seria a fome ou a guerra, únicos meios para restabelecer o equilíbrio.

Em 1898, a questão voltou à tona nos meios científicos através do discurso de Sir William Crookes, descobridor do tálio. Enquanto presidente da British Association for Advancement of Science, anunciou uma iminente catástrofe alimentar, nas décadas seguintes. Segundo Crookes, o aumento da população ultrapassava, largamente, a capacidade de aumento das colheitas dos Estados Unidos e da Rússia, principais produtores de trigo, que seriam obrigados, em breve tempo, a parar de exportar para abastecer as necessidades internas. A Inglaterra, grande importadora de cereais, continuou ele, era particularmente vulnerável, pois "a primeira arma em tempo de guerra é o alimento". Pleiteando a intensificação da cultura de trigo na Inglaterra, ele apontou o ponto fraco: onde encontrar os adubos azotados necessários? Nem adiantava pensar nas reservas sul-americanas de guano ${ }^{2}$ e de salitre chileno ${ }^{3}$, continuou o sábio, pois estas seriam brevemente extintas. A única solução, salientava ele com justa razão, seria fabricar adubos azotados usando amoníaco, sendo este último sintetizado a partir do azoto da atmosfera, reserva inesgotável.

Os comerciantes de Londres, evidentemente, não tinham esperado essa intervenção alarmista para entender a importância estratégica do nitrato sulamericano. Principalmente os que tinham feito comércio lucrativo com John Thomas North, dito "rei do salitre", pois detinha praticamente, o monopólio do salitre do Chile até às vésperas da sua morte, ocorrida dois anos antes do discurso de Crookes. North havia sido o beneficiário da Guerra do Pacífico (18791883), conflito durante o qual o Chile despedaçou a Bolívia e o Peru, sequestrou os depósitos de nitrato (que passou, desde então, a ser "salitre chileno") e confiou a sua exploração a North, que 
se transformou, a partir daí, em um dos mais ricos ingleses. Mas o guano e o salitre não serviam apenas para adubos: eram fundamentais, sobretudo, para fabricar explosivos.

O discurso de Sir William Crookes não trouxera, portanto, novidades para os negociantes. Mas serviu para realçar a crise do nitrato que se esgotava rapidamente, fazendo o seu preço subir $25 \%$ entre 1902 e 1904. A principal repercussão da palestra de Crookes foi entre os cientistas que começaram a procurar uma maneira de fixar o azoto atmosférico.

\section{Síntese do amoníaco}

No início do século vinte, os sábios alemães eram particularmente favorecidos no campo das investigações científicas: o seu país tinha resolvido o problema que sempre assolou as pesquisas, o financiamento. Incentivados pelo governo, banqueiros e industriais agiam em sintonia: os industriais compravam patentes e contratavam cientistas talentosos, enquanto os bancos forneciam os fundos. Formou-se assim um complexo industrial-bancário-universitário de rara eficiência.

Um dos primeiros químicos a obter uma síntese do amoníaco foi Friedrich WiIhelm Ostwald, futuro Nobel da química (1909). Em 1900, ele propôs uma reacção catalisada pelo ferro à BASF (Badische Anilin und Soda Fabrik). Encarregados de analisar a viabilidade industrial da ideia, Carl Bosch e Alwin Mittash, dois engenheiros da empresa, deram um parecer negativo, pois não conseguiram reproduzir os resultados esperados. Nesse ínterim, o francês Henri Le Chatelier tentava, também, efectuar a mesma reacção. Infelizmente, abandonou precipitadamente as suas experiências, em 1901, após uma explosão no laboratório. Mais tarde, o sábio deplorou assim essa decisão: "Foi a maior falta de lucidez da minha vida".

Em 1904, Haber e o inglês Robert Le Rossignol preocuparam-se com o assunto. Variando a temperatura e a pressão da reação, conseguiram um resultado interessante mais ou menos a $200^{\circ} \mathrm{C}$ e 200 atmosferas. A despeito de tais condições, desconhecidas até então em laboratórios, a reacção continuava lenta e, por conseguinte, de pobre rendimento. Para acelerá-la, testaram inúmeros catalisadores e caíram, por acaso, no ósmio, metal muito raro.

Em 1908 Haber mostrou para a BASF um equipamento que produzia 100 centímetros cúbicos de amoníaco por hora. Começou então uma dura negociação. A companhia, por precaução, comprou imediatamente todo o ósmio disponível no mercado, o que a colocou em posição de força: quem possuísse o ósmio possuía o segredo do processo (raciocínio válido se não houvesse outro catalisador capaz de substituir o ósmio). Ao mesmo tempo, Carl Bosch e Alwin Mittasch investigavam, sem limite de crédito, outros catalisadores possíveis.

Vendo o tempo passar, Haber informou a BASF que a sua rival, a Hoechst, também estava interessada na descoberta. A jogada foi boa: acto contínuo, a BASF ofereceu-lhe participação nos benefícios e um rendimento anual de 6000 marcos, ou seja, dobrava o salário do Haber Mas, poucos meses depois, o sábio mudou de ideia, após um encontro com o banqueiro e presidente da Auer, Leopoldo Koppel, judeu convertido, que se tornou rapidamente seu protector. Haber informou então a BASF que o seu novo amigo the propunha a direcção das pesquisas da Auer por um salário de "seis dígitos". Bluff ou não, semelhante notícia alarmou a BASF. Mesmo já tendo comprado a patente, não era de bom augúrio a colaboração de Haber com um concorrente potencial. Principalmente porque Carl Bosch estava com dificuldades para viabilizar industrialmente o processo de Haber. Assim, a BASF jogou um derradeiro trunfo: subiu o salário de Haber para 23000 marcos, mas colocando um senão à colaboração dele com a Auer, estabelecendo a promessa de oferecer preliminarmente à BASF todo e qualquer novo projecto de pesquisa.

\section{Anos antes da guerra}

Leopoldo Koppel foi um mecenas que procurou estabelecer boas relações com os Estados Unidos.
Em 1905, fundara a Fundação Koppel, cópia do Instituto de Andrew Carnegie, filantropo americano que tanto fizera pela ciência no seu país. Quando, em 1910, o Imperador alemão planeou fundar o Instituto Kaiser Wilhelm, organização pública, semi-privada destinada a atrair fundos privados para a pesquisa, dirigiu-se naturalmente a Koppel. Entusiasmado com a ideia, Koppel recomendou ao Kaiser confiar a responsabilidade do Instituto Kaiser Wilhelm de Físicoquímica e Electroquímica a Fritz Haber. Assim, em 1911, ele foi para Berlim dirigir este Instituto.

Na capital alemã, Haber privou com industriais e políticos de relevo, a começar pelo Imperador. A sua influência na vida científica alemã tornou-se decisiva. Doce vingança para um homem que tinha sofrido tanta humilhação antes de conseguir uma cátedra de professor no Instituto Técnico de Karlsruhe, em 1906.

Pouco tempo depois, Haber foi consultado sobre a oportunidade de enviar Max Planck e Walther Nernst a Zurique a fim de convidar Albert Einstein a vir para a Alemanha. O pai da relatividade, que se tornara grande amigo de Haber, veio a Berlim em 1913, no mesmo ano em que foi aberta a primeira fábrica de amoníaco.

Com efeito, Carl Bosch havia trabalhado duro durante quatro anos para superar dificuldades imprevistas: para passar de uma ideia de laboratório à produção industrial, o caminho estava repleto de percalços. Bosch, ajudado por centenas de pesquisadores e técnicos, experimentou mais de 20000 catalisadores antes de encontrar um conveniente 4 . Depois, teve de construir compressores gigantescos capazes de funcionar vinte e quatro horas por dia. Tal proeza trouxe-lhe o Nobel da química em 1931, prémio que compartilhou com Friedrich Bergius. Carl Bosch transformou profundamente o método inicial, mas mostrando falta de modéstia, causou a fúria de Haber ao afirmar "não sobrou nada de Haber aqui".

Como já foi dito, a fábrica inaugurou-se em 1913, apenas alguns meses antes da Primeira Guerra Mundial (1914- 
1918). A sua produção inicial, entre três e cinco toneladas de nitrato por dia, aumentou rapidamente: em 1918 ultrapassava 300000 toneladas anuais, quantidade superior às importações anteriores à guerra. Sem essa fábrica, a Alemanha teria sido derrotada antes de 1916 por falta de nitrato, devido ao bloqueio marítimo inglês.

\section{Haber durante a guerra}

28 de Junho de 1914: o arquiduque da Áustria, François-Ferdinand, morreu em Sarajevo, vítima de atentado de um partidário da causa sérvia.

Um mês depois, os diplomatas desapareceram atrás dos soldados: a Alemanha e a Áustria-Hungria de um lado, a França, a Inglaterra e a Rússia de outro, começaram a matar-se.

A população de Berlim, entusiasmada, aplaudiu quando o exército alemão violou as fronteiras da Bélgica neutra, em Agosto. Diante da causa patriótica, as querelas internas desapareceram, mesmo quando as tropas do Kaiser massacraram uma parte da população de Louvain.

Tamanha brutalidade suscitou uma justa indignação na França e na Inglaterra. Entretanto, na Alemanha, a elite intelectual apoiou o exercito através de um "Apelo ao mundo civilizado". Tal manifesto, assinado (às vezes sem leitura preliminar) por 93 personalidades do mundo cultural, afirmava: "sem nosso militarismo, a civilização alemã teria sido destruída". Qualificando de "justo" o castigo que os soldados alemães "foram obrigados a infligir aos bandidos" de Louvain, os signatários interpelavam directamente os seus colegas franceses e ingleses assim: "(Aquele) que não tem medo de excitar mongóis e negros contra a raça branca ${ }^{5}$, oferecendo assim ao mundo civilizado o mais vergonhoso espectáculo que se pode imaginar, é certamente o último a ter direito de reivindicar o papel de defensor da civilização europeia". Em baixo do manifesto estão os nomes de vários Prémios Nobel, ou futuros premiados: além de Fritz Haber, Wilhelm Roëntgen (física, 1901), Emil Fischer (química, 1902), Philipp Lenard (fisica, 1905), Paul Ehrlich (medicina,
1908), Wilhelm Ostwald (química, 1909), Wilhelm Wien (física, 1911), Richard Willstäter (futuro Nobel da química, 1915), Max Planck (futuro Nobel da física, 1918) e Walther Nernst (futuro Nobel da química, 1920).

Mas o resultado desta proclamação foi negativo. Os sábios ingleses e franceses (a quem o apelo era destinado) concluíram que não existia mais nada em comum entre eles e os cientistas alemães. Com excepção de algumas trocas de cartas, as relações entre os pesquisadores dos dois lados foram cortadas.

\section{As armas químicas!}

Terminada a primeira batalha do Marne, alguns generais alemães já sabiam que a vitória na frente ocidental seria difícil. o que deveria ter sido um passeio para as tropas do Kaiser, transformou-se em guerra de trincheiras, onde os soldados se atolavam.

O chefe do Estado Maior, Erich Von Falkenhayn, confiou, em Setembro de 1914, a Walther Nernst uma pesquisa sobre gases irritantes e lacrimogéneos para obrigar os soldados aliados a sair das posições e praticar uma guerra aberta. Nernst revelou-se incapaz da tarefa, e Fritz Haber propôs-se para o encargo.

Tratava-se, no entanto, de uma matéria delicada: dois tratados assinados em Haia, em 1899 e em 1907, ratificados em seguida pela Alemanha, tinham proscrito a utilização de gases venenosos. O primeiro texto estipulava que "os signatários concordam em abster-se de usar projécteis cujo único objectivo seja a difusão do gás asfixiante ou letal", e o segundo interditava o uso de venenos ou de armas tóxicas nas acções militares. Estariam os gases lacrimogéneos pouco concentrados igualmente proibidos? De qualquer modo, o exército alemão justificou a sua decisão de fabricar gás lacrimogéneo dizendo que o exército francês foi o primeiro a usá-lo.

Desde o início, Haber encontrou sérias dificuldades. Em Dezembro, uma explosão no seu laboratório matou o jovem químico, Otto Sackur. No mês seguinte, um ensaio com bombas carregadas de lacrimogéneo revelou-se ineficaz. Falkenhayn decidiu então encobrir a produção de venenos de guerra. Para facilitar esta missão, o Kaiser exigiu pessoalmente a nomeação de Haber como capitão, contra a vontade da hierarquia militar. Embora seja um posto sem comando, o sábio ficara eufórico: era uma recompensa inédita para um homem nascido judeu.

O cloro transformou-se no centro da operação: a indústria de corantes produzia-o em grande quantidade. Pesado, este gás voa lentamente quando derramado no chão, dando assim tempo ao vento de carregá-lo para o alvo selecionado. Falkenhayn captou imediatamente que esse procedimento contornava a interdição da utilização de "projécteis". Existiria alguém tão estúpido para não ver que um produto esparramado no solo não era transportado por projéctil?

Haber organizou uma equipa com Walther Nernst e outros futuros prémios Nobel, os mais activos sendo James Franck (física ,1925), Gustavo Hertz (física, 1925) e Otto Hahn (química, 1944). Não se pode tampouco esquecer Carl Duisberg, director da Bayer, que colocara o aparelho produtivo da empresa à disposição da causa. Por outro lado, Haber deparou-se com a recusa de Emil Fisher: "Desejo-lhe o fracasso, do fundo da minha alma patriótica", disse este último a Haber, fazendo este sombrio prognóstico: "Os outros farão a mesma coisa 6".

Escolheu-se Langermarck (na Bélgica) para o primeiro ensaio. Em Abril de 1915, a maioria dos soldados que defendiam a cidade eram argelinos e canadenses, arrolados pelos exércitos franceses e ingleses. Sob o comando pessoal de Haber, os alemães, durante a noite, soterraram centenas de barris de cloro, aproximadamente 170 toneladas, distribuídos numa linha de cerca de seis quilómetros. De charuto na boca, ele mostrava cuidadosamente os melhores lugares para enterrá-los. Durante vários dias, os alemães esperaram que o vento soprasse na boa direcção e com boa velocidade: se fosse muito forte, o veneno dispersar-se-ia sem ter tempo de agir; se fosse muito fraco, os atacantes correriam o risco de um retorno perigoso de 
emanações venenosas. Assim, o ataque só ocorreu no dia 22 de Abril: Falkenhayn, impaciente, já tinha retirado uma parte das tropas, enfraquecendo o potencial ofensivo alemão.

Tão logo abertos, os tambores largaram uma nuvem esverdeada que, lentamente, seguiu na direção dos franceses. 0 efeito foi terrível: o veneno corrói bocas, olhos e brônquios, causando hemorragia. Asfixiados, muitos homens, com as duas mãos na garganta, sem fôlego, corriam cuspindo sangue. Outros, cegos, davam pequenos pulos, caíam, e iam morrer, lentamente, no meio de grande sofrimento. Alguns soldados que não tinham sido atingidos, tentavam socorrer os amigos e eram colhidos por metraIhadoras. Nada é de surpreender que muitos soldados abandonassem as posições, procurando ar respirável, abrindo brechas nas defesas.

As tropas do Kaiser aproveitaram para tomar as trincheiras abandonadas: a sorte da guerra estava por um fio. Mas as guarnições que Falkenhayn retirara faziam falta. Além disso, os alemães caíram na própria ratoeira: sobrava cloro nas depressões do terreno. Isto obrigou-os a retirarem-se, permitindo aos Aliados reorganizarem-se. No dia seguinte, estes Iutaram com determinação: era uma resistência redobrada pela indignação. No dia 24 de Abril, novos barris de cloro foram abertos, desta vez contra os ingleses. Mas, o efeito surpresa deixara de existir. Em 27 de Abril, terminada a batalha, os Aliados haviam retomado parte do terreno perdido, mesmo à custa de baixas pesadas: pelo menos 15000 , dos quais 5000 mortos. (Note-se que vários historiadores negam estes números, e dividem-nos às vezes por dez).

Este crime de guerra, que sujará para sempre o nome de Fritz Haber, repercutiu-se de maneira terrível na sua família. De volta a casa, na noite de 1 de Maio, a meio de uma violenta discussão, a sua esposa indignada pegou num revólver e matou-se. A detonação acordou o filho de catorze anos que aterrorizado tentou socorrer a mãe moribunda, banhada de sangue. Contudo, será obrigado a enterrá-la sozinho: ao amanhecer, Fritz Haber partiu para a frente oriental 7 .
Em 1917, Haber casou-se com uma jovem mulher, Charlotte Nathan, que Ihe deu dois filhos, entre os quais Ludwig, actualmente historiador de ciências, especializado em armas químicas.

Um ano antes desta união, Fritz Haber tinha começado a dirigir uma fundação destinada a melhorar as novas armas. Por outras palavras a descobrir outros gases venenosos. Conscienciosamente, assumiu essa função até o fim da guerra, tendo sob sua responsabilidade cerca de 200 pesquisadores. "O Alto Comando encontrou em Haber - dirá Ludwig acerca de seu pai - uma mente brilhante e um organizador extremamente enérgico, determinado e talvez até mesmo, inescrupuloso ${ }^{8 "}$.

Haber desenvolveu o uso de substâncias ainda mais mortais que o cloro, como o fosgénio e a yperite ${ }^{9}$. Além disso, não se esqueceu de aumentar a produção de amoníaco, matéria prima indispensável para as munições, bem como para as suas finanças.

Hoje, sabemos que a guerra química não deu a vitória à Alemanha. Emil Fischer tinha razão: em pouco tempo, os beligerantes polvilhavam-se mutuamente com gases venenosos.

\section{Haber após a guerra}

Novembro de 1918: o império alemão desmoronou e a república foi proclamada.

Procurado como criminoso da guerra, Haber refugiou-se na Suíça, onde obteve a nacionalidade, privilégio reservado às pessoas abastadas.

Em Novembro de 1919, recebeu o Nobel da química relativo ao ano 1918 , o que causou, imediatamente, uma onda de protestos por parte dos cientistas franceses, ingleses e americanos, que denunciaram a Academia Sueca. Este debate abalou ainda mais Haber, já profundamente deprimido pela derrota da Alemanha. No entender dele, os gases tinham objectivos humanitários porque visavam encurtar a guerra.

Obrigada a explicar-se, a Comissão do Prémio Nobel assegurou que a distinção recompensava somente o inventor da síntese do amoníaco, graças à qual a fome podia ser combatida no mundo. Sem dúvidas, os adubos obtidos por intermédio do processo Haber-Bosch permitem hoje alimentar pelo menos dois mil milhões de indivíduos.

No entanto, a Comissão comprometeu-se novamente dois anos mais tarde ao atribuir o Nobel da química a Nernst, igualmente declarado criminoso de guerra. É verdade que, em Novembro de 1921 (data do anúncio da atribuição do Prémio Nobel a Nernst referente a 1920), os Aliados já não procuravam os dois homens. Três anos após a guerra, talvez fosse imoral continuar a persegui-los: todos já sabiam que os Aliados também haviam praticado intensamente a guerra química. Além do mais, as potências vitoriosas não desejavam desacreditar excessivamente uma arma que poderia ser útil nas colónias.

Haber retornou à Alemanha, retomando as suas antigas funções e transformando o seu instituto num importante centro internacional de pesquisas, onde se publicavam centenas de jornais científicos de alto nível.

Na década de 1920, Haber tinha um novo objectivo: salvar a Alemanha do desastre económico. Delírio megalómano? De modo nenhum, dizia ele. Não é verdade que ele já salvara o país uma vez com a síntese do amoníaco? A sua nova ideia consistia em tirar ouro do mar para pagar as pesadas reparações da guerra. Em 1923, principalmente, empreendeu uma campanha de extracção, mas o projecto revelou-se economicamente desastroso ${ }^{10}$.

No terreno das pesquisas, Haber recomeçou a produzir venenos, como antigamente, com a desculpa de lutar contra as pragas dos silos, os roedores e os insectos. Entretanto, atrás dessa cortina, ele elaborava na realidade novas armas químicas, para que a Alemanha não perdesse a dianteira para outros países. Assim, a sua equipa criou o Zyklon B. Seria para ele possível prever que esse veneno seria usado nos campos de exterminação nazis, durante a Segunda Guerra Mundial? Seria para ele possível imaginar, que muitos de seus familiares e amigos seriam vítimas desse gás? 


\section{Haber durante o nazismo}

Em meados da década de 1920, dois eventos quase simultâneos perturbaram a vida de Haber: um forte prejuízo financeiro e o divórcio com a segunda esposa. Talvez isso o tenha impedido de ver a ascensão do nazismo nos círculos culturais. Se a viu, minimizou-a.

Entretanto, as agressões começaram desde o Outono de 1920 quando Philipp Lenard e Johannes Stark atacaram a relatividade de Einstein a pretexto de ela ferir o "bom senso", argumento que evoluiu rapidamente: sem demora, a teoria foi catalogada de "fraude judaica", acusação que os nazistas imediatamente assumiram.

Em 1924, os actos racistas aproximaram-se ainda mais de Haber: o seu meIhor amigo, Richard Willstätter, Nobel da química em 1915, renunciou de maneira estrondosa ao trabalho que fazia em Munique. Indignado pelo comportamento do conselho de ensino da universidade que tinha recusado um professor judeu, ele abandonou, para sempre, o seu laboratório. De qualquer modo, a estada de Willstätter na universidade de Munique havia sido sempre dolorosa. Em 1915, o rei Ludwig da Bavária, nervoso, dissera para o ministro que assinava sua nomeação como professor: "Esta é a última vez que permitirei a contratação de um judeu 11".

Contrariamente a Einstein, Haber não tomou partido contra a ascensão do nacional-socialismo. Quando Hitler chegou ao poder, em Janeiro de 1933, os dois estavam no exterior: Einstein em Pasadena (Estados-Unidos) e Haber em Cap Ferrat (França) por razões médicas. Imediatamente, Einstein denunciou o hitlerismo, enquanto Haber preparava o seu regresso. No caminho de volta, cruzou-se com inúmeros intelectuais que fugiam do nazismo: em apenas um ano, em 1933, mais de cem cientistas de alto nível deixaram a Alemanha, entre eles vários Prémios Nobel. Tal hemorragia intelectual, só podia enfraquecer o país. Em 1979, Raymond Aron fez uma lúcida observação a Fritz Stern: "O século vinte poderia ter sido o século da Alemanha"12. Para medir o desempenho do país, basta citar uma cifra: de 1901 a
1932, isto é, da criação do Prémio Nobel até a chegada de Hitler ao poder, a Alemanha obteve 35 premiados, a esmagadora maioria deles em física, química e medicina. Mesmo a derrota na Primeira Guerra Mundial não conseguira atrapalhar esta extraordinária realização.

Além dos círculos científicos, a fuga de cérebros atingiu também os meios literários e artísticos: Bertolt Brecht, por exemplo, fugiu primeiro para a Dinamarca, em seguida para a Finlândia, onde ficou pouco tempo; os cineastas Fritz Lang, Max Ophuls foram para a França, etc. Estes lugares de asilo eram atípicos, a maioria dos exilados começava a fuga atravessando o Atlântico. Aliás, o director do Institute of Fine Arts (New York) não declarou: "Hitler é o meu melhor amigo, ele sacode a árvore, eu colho as maçãs" 13 ?

\section{O Fim}

Pouco após o incêndio do Reichstag (25 de Fevereiro de 1933), Hitler começou uma selvagem repressão, visando inicialmente os comunistas, mas descambando imediatamente sobre qualquer democrata, socialista e sindicalista, sem esquecer grupos étnicos ou religiosos como os ciganos e os judeus.

Com o intuito de "purificar" a administração, um decreto exigia a demissão dos não-arianos. Previa, entretanto, algumas excepções, principalmente para os veteranos de guerra, categoria em que se encontravam Fritz Haber e James Franck, ambos envolvidos com as armas químicas. Eles podiam permanecer, mas deviam demitir os colaboradores judeus, baptizados ou não.

James Franck, achando que se aceitasse essa ignomínia não poderia nunca mais olhar-se num espelho, renunciou à sua função. Numa carta escrita a Haber em Abril, afirmava que não recorreria "a esta migalha de caridade que o governo ofereceu aos veteranos de guerra da raça judaica". Fazendo clara alusão às hesitações de Haber, ele acrescentava: "Respeito e compreendo a posição daqueles que queiram permanecer em seus postos hoje, mas também é preciso que haja pessoas como eu14. Abala- do, Haber também renunciou, acto cuja validade, entretanto, deveria começar... em 1 de Outubro

Ele gostaria de ter ido morar para a Suíça, mas por falta de emprego, foi para Cambridge. Não suportando o clima inglês, mudou-se para Basileia onde morreu em Janeiro de 1934.

Que sentimentos devemos ter a respeito de Fritz Haber? Admiração pelo cientista ou abjeção pelo criminoso? Além de ter falido na tentativa de aliar integração e patriotismo, ele ilustra, perfeitamente, o paradoxo da ciência: toda a pesquisa pode ser ao mesmo tempo fonte de progresso e de infortúnio. O mesmo homem que inventou a síntese do amoníaco usou a ciência para fabricar armas venenosas.

\section{BIBLIOGRAFIA}

GILLISPIE C. C., Dictionary of Scientific Biography, Charles Scribners Sons, New York

GORAN Morris, The Story of Fritz Haber, University of Oklahoma Press, 1967; "The Present-Day Significance of Fritz Haber”, American Scientist, Julho 1947.

LEPICK Olivier, La grande guerre chimique: 1914-1918, PUF, Paris, 1998.

Nobel Lectures, Chemistry 1901-1921, Elsevier Publishing Company, Amsterdam, 1966 (disponível no site: http://nobelprize.org/chemistry/laureates/1918/haber-bio.html. O discurso de Fritz HABER no dia da recepção do Nobel, The synthesis of ammonia from its elements, http://nobelprize.org/chemistry/laureates/1918/haber-lecture.html)

OAKES Elizabeth $A$ to $Z$ of Chemists, New York, Facts On File, Inc. 2002.

PERUTZ Max « Le Cabinet du Dr. Fritz Haber », La Recherche n²97, dezembro de 1997.

RIVAL Michel, Aprendizes de Feiticeiro. O Armamento no Século XX: Fritz Haber, Wernher von Braun, Edward Teller Editorial Caminho, Lisboa, 2002,

SMIL Vaclav, Enriching the Earth : Fritz Haber, Carl Bosh and the Transformation of the World Food Production, MIT press, Cambridge, 2001.

STERN Fritz, O Mundo Alemão de Einstein, Companhia das Letras, São Paulo, 2004.

StOltzenBeRg Dietrich, Fritz Haber: Chemist, Nobel Laureate, German, Jew: A Biography, Heritage Press, 2004. 
E ainda as seguintes obras do autor:

(com Joëlle Fontaine), A imagem do mundo, dos babilônios a Newton, tradução de (L'Image du monde des Babyloniens à Newton por Dorothée de Bruchard), Companhia das Letras, São Paulo, 2003.

L'Image du Monde de Newton à Einstein, Vuibert Adapt, Março 2005.

La science au Péril de sa vie, les aventuriers de la mesure du monde, Vuibert Adapt, Paris, 2001. (Prémio especial do livro de astronomia em 2002)

NOTAS

(1) Citado por Fritz Stern em O Mundo Alemão de Einstein, ver bibliografia, p. 97.

(2) "Guano", palavra de origem quéchua, significa "esterco de pássaro". Acumulado em grande quantidade nas costas do Peru e do norte do Chile, ele é constituído de sais amoniacais, de ácido úrico, de oxalato de cálcio, etc. Diz-se que os incas já o utilizavam na agricultura.
(3) O salitre chileno é o nitrato de sódio.

(4) O catalisador era ferro em pó misturado com pequenas quantidades de cálcio, de óxido de alumínio e de potássio.

(5) Trata-se de uma alusão aos soldados recrutados pela França e pela Inglaterra nas colónias.

(6) Citado por Thomas Levenson, Einstein em Berlim, Objetiva, Rio de Janeiro, 2003, p. 140 (que cita Jeffrey Allen Johnson, The Kaiser's Chemists, Chappel Hill, Carolina do Norte, 1990, p. 190). Na realidade, Fischer vai acabar colaborando com uma Fundação dirigida por Haber. No final da guerra, ele irá suicidar-se, magoado pela morte dos filhos na frente de batalha, mas também provavelmente, pela sua participação na guerra química.

(7) Hermann, filho de Clara e Fritz Haber, ficou traumatizado para sempre. Em 1947, também ele se suicidou nos Estados Unidos, acto imitado pouco depois, pela sua própria filha.

(8) Citado por Fritz Stern, p. 146.
(9) Extremamente tóxico, a yperite (ou "gás mostarda"), sintetizado pela primeira vez em 1860 (segundo alguns 1822), foi inicialmente usado em 1917 em Ypres (onde recebeu o seu nome). Para se protegerem, os soldados deviam vestir, além das máscaras, roupas impermeáveis que atrapalhavam os movimentos. Utilizado pelos dois beligerantes, foi um dos mais importantes venenos da Primeira Guerra Mundial.

(10) Estas pesquisas foram feitas de 1921 a 1927. Haber pensava que havia $6 \mathrm{mg}$ de ouro em cada tonelada de água do mar. Mas só achou 0,004 mg, isto é, menos de um milésimo.

(11) Citado por Fritz Stern, p. 173

(12) Citado por Fritz Stern, op. cit. p. 9

(13) Citado por Wilfried McClay, "Weimar in America", American Scholar, n 55 [1986], 119-128, p. 120

(14) Citado por Stern, p. 190

Actualidades Científicas

\section{Células de combustível}

Cientistas americanos desenvolveram um procedimento que pode conduzir a um incremento significativo no desempenho de células de combustível, e que leva igualmente a uma diminuição de custos. O revestimento do cátodo com uma fina camada de platina, em alternativa à utilização de um cátodo em metal maciço, possibilita um aumento na eficiência da ordem de 10\%, ao mesmo tempo que leva a uma redução na utilização da platina, o que reduz significativamente os custos.

As células de combustível são consideradas como uma fonte de energia mais limpa do que os sistemas convencionais centralizados, já que proporcionam a geração de energia no local, dispensando o transporte da energia desde a fonte até ao utilizador, passo este geralmente muito ineficiente. Por outro lado, não implicam a queima de combustíveis fósseis, ou seja não produzem poluentes no local de geração.
Deste modo, como afirma o investigador Manos Mavrikakis da Universidade de Wisconsin/Madison, "Qualquer avanço que possibilite a redução dos custos dos materiais usados nas células de combustível de baixa temperatura - em grande parte devidos ao custo de metais nobres como a platina - conduziria inevitavelmente ao aumento da competitividade da tecnologia e tornaria mais próxima a sua aplicação na vida quotidiana".

No entanto, as células de combustíve não podem ser 100\% eficientes, e o trabalho dos investigadores direcciona-se no sentido de procurar formas de reduzir as perdas de energia que ocorrem e que segundo Mavrikakis se devem em aproximadamente $60 \%$ à ineficiência da redução do oxigénio.

Assim, Mavrikakis e Ye Xu da Universidade de Wisconsin/Madison e Junliang Zhang, Miomir Vukmirovic, e Radoslav Adzic do Laboratório Nacional de Brookhaven em Upton, Nova York, estudam formas de reduzir a quantidade de cata- lisador de platina utilizado nas células de combustível. Experimentaram catalisadores com teores de platina gradualmente inferiores e observaram que existe actividade electrocatalítica para a reacção de redução de oxigénio (ORR) com eléctrodos constituídos por suportes menos dispendiosos (como ouro, paládio, ruténio e irídio), revestidos por uma monocamada de platina.

Na realidade, os investigadores concluíram que os cátodos bimetálicos operam de forma mais eficiente na reacção ORR do que os eléctrodos de platina, apesar de conterem apenas uma pequena fracção deste metal, localizado na monocamada. Adzic e Mavrikakis sugerem que um aumento na eficiência, conjugado com uma diminuição dos custos dos cátodos bimetálicos podem levar ao desenvolvimento de uma alternativa viável às actuais células de ORR. (adaptado de webzine Reactive Reports (2005) 44).

Paulo Brito 
A TA INSTRUMENTS é lider mundial em reologia com uma focagem sem paralelo na indústria e investigação.

o compromisso com a inovação é comprovado; o desejo de fazer medidas reológicas melhor do que os seus concorrentes comprova-se pelos contínuos avanços nos seus diferentes produtos. A aquisição da firma Rheometrics permite a oferta de todos os tipos de sistemas existentes no mercado, desde sistemas operando a tensão controlada como sistemas operando a deslocamento controlado. O modelo AR 2000 é o equipamento mais vendido no mercado. Esta unidade possui capacidades de medição sem comparação e um conjunto de acessórios único. Entre outras, podem citar-se:

- Motor de arrastamento, modelado permitindo uma vasta gama linear de torções

- Inércia de baixo valor para o melhor controle de tensão e deslocamento

- Controle directo da tensão e oscilação em toda a gama de trabalho do equipamento

- Desenho ultra robusto do corpo do equipamento

- Transdutor de força manual separado

- Electrónica isolada do resto do equipamento

- Sistemas periféricos de troca rápida e identificação automática (Smart Swap)

- Representação em tempo real da forma de onda em oscilação

- O único sistema de tensão controlada disponível num corpo único de alumínio

\section{UM Nível Superior em Calorimetria}

A TA Instruments fabrica diversos tipos de equipamentos na área da calorimetria. Para além dos calorímetros de varrimento, fornece também equipamento de análise termogravimétrica, equipamentos combinados de DSC/TG, DMA e TMA. O DMA Q800 é o estado da arte em análise dinâmico/mecânica.

A unidade utiliza uma tecnologia semelhante à dos reómetros, de atrito reduzido.

O deslocamento é medido utilizando um descodificador óptico que proporciona elevada sensibilidade e resolução. A unidade é utilizada na caracterização de propriedades viscoelásticas de vários tipos de materiais sólidos e é ideal para aplicações em materiais de forte resistência incluindo compósitos.

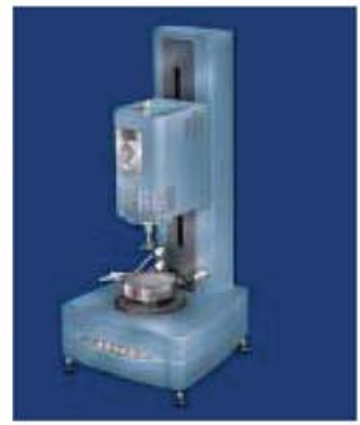

\section{TECNOLOGIA T 0 PARA CALORIMETRIA DIFERENCIAL DE VARRIMENTO (DSC)}

Um desenho superior para desempenhos de alto nivel. 0 novo sensor $\mathrm{T}_{0}$ melhora a resolução em $300 \%$ comparativamente aos sistemas tradicionais. A estabilidade da linha de base e a sensibilidade melhoram de uma ordem de magnitude em relação também aqueles sistemas. A possibilidade de automação dá ao utilizador resultados rápidos, reprodutiveis e exactos.

A utilização do chamado DSC modulado, torna a análise dos dados. ainda mais simples, trazendo mais luz à análise de alguns eventos de difícil interpretação.
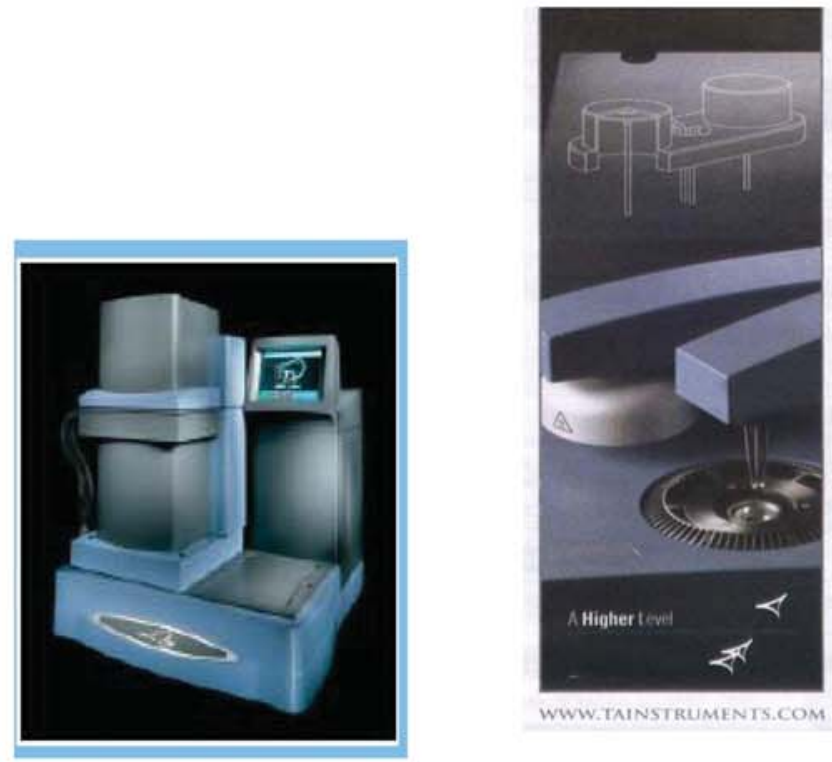
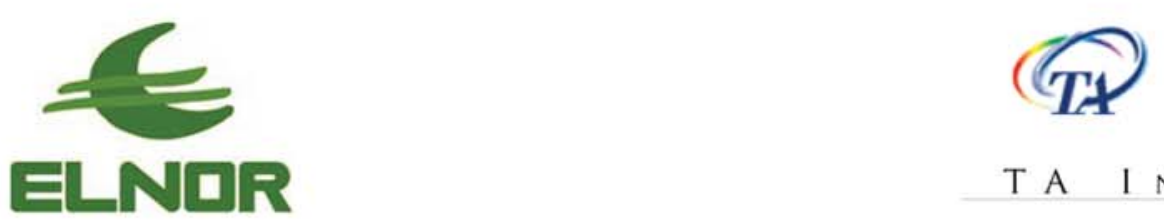

ELNOR - Equipamentos Técnicos e de Laboratório, S.A.

B R.D.Frei Jerónimo de Brito e Melo No 835 • 4465-642 LEÇA DO BALIO • PORTUGAL

$\triangle$ P.O.Box $1019 \bullet 4470$ MAIA CODEX • PORTUGAL

- Phone: (351 22) 9050400

- Fax : (351 22) 9050499 